\title{
Chapter 8 \\ Developing a repertoire of activism strategies
}

Lenia Toledo Rasgado attended the very first Camino de la Iguana literacy workshop that occurred in 2012 in Juchitán when she was in her late teens. A cousin from Mexico City was visiting and was interested in going, so she and her sister went along too. Growing up in the center of La Ventosa, a village 15 minutes outside of Juchitán, her parents had discouraged her from speaking Zapotec. She had never used Zapotec in school, and they had been forbidden to use it when she attended primary school in La Ventosa. Over the years she had picked up a lot nonetheless, and as a young adult she felt she could more or less get by, although she was more comfortable in Spanish. When she was in secondary school in Juchitán a member of the collective Comité Melendre had given a presentation about Zapotec history in her class, which had inspired her interest and desire to learn more. She admired Zapotec poets and cultural activists, especially the female writers Natalia Toledo and Irma Pineda.

After participating in the 2012 Camino de la Iguana workshop she began writing poetry but felt that she did not know the writing system well enough, and when the Camino de la Iguana was offered in La Ventosa in the fall of 2013 she attended again. I was also attending and joined her and the other students in the activities and the final convivio, or closing celebration. The workshop was held in the brand new "Bacusa gui" (firefly) cultural center (during the workshop participants learned that it should be spelled "bacuza gui" in the popular alphabet, although this didn't motivate anyone to repaint the sign). The cultural center had been completed just a few months before as a corporate social responsibility project by a Spanish-owned wind farm whose windmills had come to fill the horizon on all sides of La Ventosa over the previous seven years. Some residents of La Ventosa had benefited economically from this development through employment or leasing land, and now had houses as big and freshly painted as the cultural center. Other residents had not benefited, and remained in one or two-room cinderblock or adobe brick houses, but with the same view of the forest of white windmill towers.

The following winter I participated in planning a language and botanythemed workshop for children in La Ventosa as part of the Smithsonian-funded project to document ethnobotanical knowledge, and I asked if Lenia would be willing to participate in it by teaching some language activities. When she readily agreed we talked about some games she could play to help children learn to use simple, daily phrases. We initially planned to conduct the workshop in one group, facilitated by Gibrán Morales, a visual artist from Oaxaca City who was

Ә Open Access. (C 2021 Haley De Korne, published by De Gruyter. (c) BY-NC-ND This work is licensed under the Creative Commons Attribution-NonCommercial-NoDerivatives 4.0 International License.

https://doi.org/10.1515/9781501511561-008 
the photographer for the Smithsonian team, myself, Lenia, her sister Citlalli, and José López de la Cruz, a senior male member of a cultural committee in La Ventosa. José had long wanted to teach Zapotec workshops for children, although he did not have pedagogical experience and his full-time job with the wind farm left him little spare time. I visited the local (monolingual) primary schools to promote the workshop. In one school the director escorted me to each classroom where he added his own words of encouragement for the children to attend the workshop after I had issued the invitation. In one classroom there were some words in English on the chalkboard that the teacher had been teaching the class as part of the 'additional language' subject in primary school. Another school director told me that he was glad that children could do something other than sit in front of the television, where they spent much of their time nowadays in his opinion.

On the first day of the 2-day workshop children poured through the door of the cultural center, and we realized we would have to split the 60 participants into two alternating groups. As I went in and out of the rooms, dealing with logistics, I saw that Lenia used a few games, and also followed form-focused teaching practices that she had experienced in the Camino de la Iguana; she wrote the 3 kinds of Zapotec vowels on a whiteboard and had children copy them, followed by drilling consonants, color-words and numbers. The children participated with enthusiasm in both the games and the drills. The younger children, 10 and below, appeared to understand very little Zapotec, while the older children knew considerably more, although none were conversant. Three young sisters who I had seen hanging around the cultural center on previous occasions were among the children who recognized and offered the most words. They were also among the children wearing the most worn-out clothing. The youngest stood out due to her wide grin, showing off a mouth of black baby teeth.

The next time I saw the sisters in the cultural center was a month later, and the older one approached and bragged to me that she knew how to count in Zapotec (a topic covered in the workshop, although she might have known it before). Great, I responded, how? She rattled off the numbers up to 10 fluently. Then she wanted to know, how are the numbers in English? The fact that foreigners like myself were interested in Zapotec had made an impression on her, but the link between foreigners and English, and the status of English in mass media and in school, were also clearly in her mind. As on many other occasions, I wondered whether the benefits gained from the presence and practices of foreign language activists, such as myself, outweighed the risks of reproducing aspects of Eurocentrism and coloniality, such as the status, privilege and mobility of Euro-descended languages and people. And, as on other occasions, 
I continued to seek ways to support local activism initiatives and to disrupt the Eurocentric logics that my presence might evoke, hoping that the benefits did outweigh the harm.

The sisters continued to attend subsequent Diidxazá workshops that were facilitated by a team of La Ventosa residents on a near-monthly basis, following from the success of the first workshop. The workshops were sponsored initially by the Smithsonian through project-leader Gabriela Pérez Báez, and eventually by donors of a crowd-funding campaign that Gabriela and I ran when the initial grant money was exhausted. The core team included Lenia and José, who had volunteered in the first workshop, and several other residents of La Ventosa who had worked in the ethnobotany project and were interested in engaging in outreach (see also Pérez Báez 2018; Purkarthofer and De Korne 2020). ${ }^{45}$ In a discussion with Lenia and team-member Reyna López López in 2017, they commented on how other members of the community had come to see them as language experts during the years that the workshops had been running; children would come to them outside of the workshop if they had questions about Diidxazá. Reyna had become a confident writer of Diidxazá prior to participating in the workshops during the years she worked as an assistant to several linguists conducting language documentation in the region. She had enjoyed developing confidence to teach these skills to children through the workshops. Several of the senior members of the workshop team noted that teaching and presenting in $\mathrm{Za}$ potec was initially difficult and made them nervous, but they had come to feel comfortable using Zapotec in public and pedagogical ways. Over several years of facilitating workshops, Lenia also became more confident in both writing and speaking Diidxazá. Some of the senior members of the workshop team commented on how her competence had improved; they had gone from viewing her as a marginal speaker to a fully accepted speaker. This represented a meaningful identity shift for Lenia, whose generation and class were widely expected to be Spanish-speaking. Figure 23 shows Lenia and Reyna in the bustle prior to a calenda [traditional procession] that they organized to mark the conclusion of the workshops in April 2017. They are holding a bunch of firecrackers to be shot off as the procession of children wound through the village. Like the participating children, they wore traditional embroidered huipil blouses, or bidaani, skirts and flowers, with formal white shirts, black trousers and red bandanas for the boys. With festive clothing, music and even firecrackers, they turned the conclusion of

45 The team consisted of Reyna López López, José López de la Cruz, Lenia Toledo Rasgado, Fernando Sánchez López, Rosaura López Cartas, and Velma Orozco Trujillo, with additional support from Gabriela Pérez Báez, Gibrán Morales Carranza, Kate Riestenberg, Kenia Velasco Gutiérrez, and myself. 


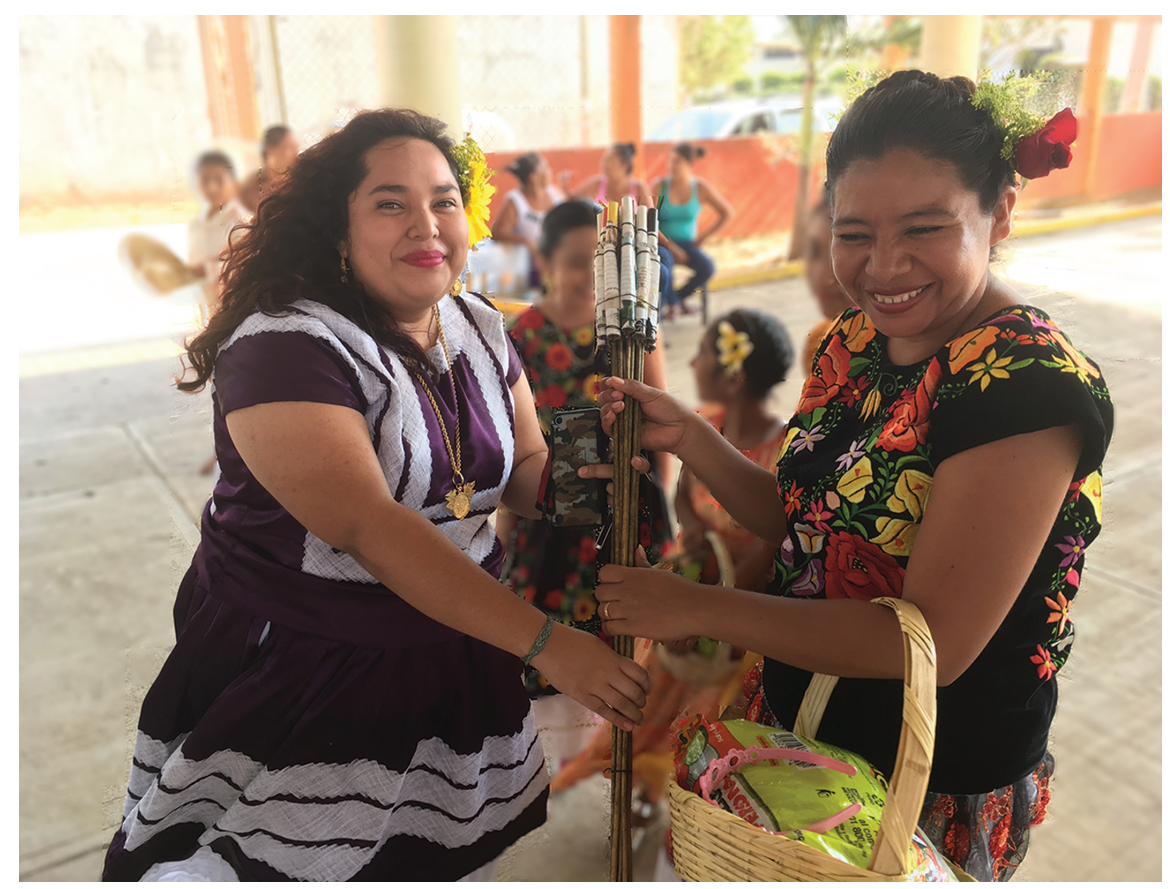

Figure 23: Lenia Toledo Rasgado and Reyna López López preparing a celebration for the end of their workshops in La Ventosa (photo April 2017).

the workshop into a full-fledged celebration that no one in La Ventosa could fail to notice. Participating children arrived early, talking together with excitement, as their parents waited on the outskirts, ready to watch.

The spaces, actors, practices and socio-political processes that make up the ecology of language in the Isthmus intertwine in countless ways, as illustrated in this description of some of the factors influencing the overlapping trajectories of a young adult Isthmus Zapotec speaker, and local and transnational language activism initiatives. The Spanish-only ideology of Lenia's parents and schooling led her to grow up more comfortable in Spanish, but encouragement from her peer group, local activists and her admiration for the literary heritage of Diidxazá helped motivate her to work towards biliteracy and bilingualism. The presence of the Smithsonian ethnobotany project in La Ventosa facilitated the creation of a workshop there, which was then supported by the existence of the cultural center (built by a foreign wind farm), money from mainly international sources, and most essentially by the interest of a few key local people, including Lenia, Reyna, and José. Motivated by my training as an educational 
linguist, I encouraged the facilitators to create a workshop focused on communicative language use. The interests and prior experiences of Lenia, and later the other facilitators, lead to the implementation of writing-centric approaches to teaching Zapotec, however, a choice which was aligned with the importance that writing has in determining language status in the Isthmus. The children remained enthusiastic and participative, and the presence of Zapotec in their linguistic repertoire was clear. However, interest in learning Zapotec in a fun, foreign-sponsored event, or locally run events and workshops, coexisted alongside an entrenched preference for Spanish (and English) in a region where Zapotec remains ideologically and materially associated with poverty and discrimination, and where meeting basic economic needs remains a pressing priority for some.

Language activism initiatives are always deeply entwined in contextual factors, and experienced differently by the various actors who initiate and participate in them. For this reason, my approach to language activism remains antiprescriptivist and constructivist, as stated in chapter 1 . The language activism framework, presented in chapter 1 and illustrated throughout this book, aims to show how some language activists have imagined and pursued positive social change through and around language use. While there is no one-size-fits-all strategy, I hope that the descriptions of language activism initiatives in schools, higher education, community-based workshops, and popular culture spaces in the Isthmus may resonate with other contexts. In previous chapters I teased apart some of the strategies employed in different contexts, discussing the characteristics of activism in each setting, and the diverse imaginaries of language equality which characterize different communities of practice. In this concluding chapter, I discuss some of the trends in relation to each strategy that may be relevant to language activism initiatives elsewhere. I also highlight how the strategies I observed more often than not flow across and among local, regional, national, and international domains, emphasizing how many language activists participate in multiple communities of practice and employ multiple intertwined strategies, as illustrated in the description of Lenia's participation in the Smithsonian-supported workshops above. For language activists in the Isthmus it is natural to develop a repertoire of strategies; some of which correspond to one area of their life, some to another.

The following section (8.1) provides a summary of the central actions and goals of the language activism strategy framework with examples from the cases described throughout the book, and a discussion of the importance of slow, local strategies as well as fast, transnational ones. I then turn to further discussion of how these strategies can lead to achieving positive social change (8.2), including the establishment of a multi-perspectival approach to 'language' and exploration of different theories of social change. I contrast problem-solving approaches to change with those which imagine a non-teleological, incremental social project, 
and consider the pros and cons of comparing and judging different forms of activism. In conclusion, I emphasize the importance of language activist networks within language politics, and the creative and contextualized strategies through which activists are shifting language politics in more inclusive, convivial and egalitarian directions (8.3).

\subsection{Language activism strategies across contexts and scales}

There are numerous ways that stakeholders in the Isthmus are working to counteract the processes of denigration that have indexed local ways of speaking and being with poverty and ignorance, and excluded them from social spaces such as education. I observed many different practices related to the teaching, learning, researching and promotion of Diidxazá, as discussed in previous chapters. My own practices and strategies as an activist were bound up in those of the people around me, although also influenced by my personal orientations, theories and priorities. As I observed, participated in and eventually initiated actions, I did not have analytical categories for what I was observing. I thought of my area of interest as activities relating to "Indigenous language promotion", and later "Indigenous language inclusion" or resistance to exclusion. Within an ethnographic monitoring paradigm, I aimed to understand what imaginaries of positive social change around language are present in the Isthmus, asking what changes do people want? What are their language imaginaries? Seeking to better understand the emic perspectives of stakeholders is the foundation of ethnographic monitoring, and is also a cornerstone of working as an ally or outside scholar (Antony-Stevens 2017). By focusing on these questions, it became clear that there are multiple perspectives and priorities to consider, whether one is looking at the scale of a primary school, a village, or a speech community spread across a region. An outsider's attempt to understand emic imaginaries can never be full nor comprehensive, but it can serve as the basis for engagement and collaboration where local stakeholders have a defining voice.

As I came to understand some of the multiple imaginaries of language, I also gained better insight into the different forms of social engagement around and through Isthmus Zapotec. In the analysis of my data, I came to look at this area as the politics of Zapotec activism, a material and discursive social project which negotiates Diidxazá use and education in various ways, and encompasses various conceptions of what Diidxazá is. The language activism strategy framework aims to capture some of the common features of this broad social project. Through this framework I aim to illustrate that possible strategies are wide-ranging and can be carried out by social actors with varying stances and 
access to resources. They may be fast or slow, visible or private, tightly planned and executed or loose and emergent. This broad perspective allows for insight into the possible alliances among activists working in different areas, as well as the importance of people who do not consider themselves to be activists but whose stances and actions do contribute to this social project. Scholar-activists cannot change the social status of minoritized languages alone. Educator-activists cannot change the social status of minoritized languages alone. Artist-activists cannot change the social status of minoritized languages alone. It is helpful for all of us to see our actions in relation to those of others, and to explore points of connection.

At least some of the examples of language activism in the Isthmus should resonate with efforts in other contexts; prying open spaces within formal education, preparing minoritized language teachers, addressing the insecurity of emergent speakers, and negotiating the opportunities and challenges of literacy are all common challenges in minoritized language promotion around the world. The ways these issues have been addressed in the Isthmus may not be appropriate in other contexts, but the effort to address these issues is hopefully one which other activists will recognize. The breadth of activism strategies, and the complex interrelations among actions, targets and characteristics are taken up in 8.1.1, 8.1.2, and 8.1.3. This discussion necessarily omits the details and dynamics of the individual activism strategies which are described more fully (although still much smaller-than-life) in chapters 3-7. In section 8.1.4, I analyze some of the trends in activism strategies across contexts, and discuss the importance of locally-grounded, slow strategies which sometimes receive less attention than faster, non-local initiatives.

\subsubsection{Strategic creating}

Ways of creating vary greatly depending on what is produced and the positionality of the creators. As laid out in the framework, language activists' creating is aimed at goals which include:

- Resources, such as the documentation and dictionaries created by researchers (chapter 3), the digital platforms created by individuals and civil society groups (chapter 7) or the didactic materials created by student teachers at the university (chapter 5).

- Events, such as the conference hosted by the Tehuantepec Faculty of Languages (chapter 3); the primary school flag ceremony (chapter 4); or the festivals of female writers and artists (chapter 7). 
- Spaces or structures, such as the weekly hip-hop radio program (chapter 7), the series of workshops that emerged from the Smithsonian ethnobotany project (described in the opening of this chapter), or the university classes teaching Diidxazá as a subject and teaching about bilingual Indigenous literature (chapter 5).

- People or identities, such as new Diidxazá readers and writers (chapter 6); certified Indigenous language teachers (chapter 5); or Isthmus Zapotec women (chapter 7).

- Communication practices, such as young adults speaking or writing Diidxazá (chapters 5, 7 and the case of Lenia described above); the use of a specific writing norm (chapters 6 and 7); or the use of a multi-dialectal norm (chapters 5 and 6).

Each of these forms of creating is influenced by some or all of the strategy characteristics in the framework, as illustrated by representative examples in Table 7 in section 8.1.4. For example, the location of the activists clearly impacts the kinds of actions they can undertake, as well as the priorities they are likely to have. As noted in chapter 3, I observed non-local researchers to be especially focused on the creation of resources, a product which can often be produced and circulated across local and international scales. In contrast, all of the spaces or structures directly related to teaching and learning Zapotec that I observed were produced through local, regional, and occasionally state-level support, including classes in cultural centers, the Faculty of Languages, the Camino de la Iguana, and public schools working to implement the state-level PTEO policy. These spaces are developed over a slower timeframe than what it takes to produce learner materials, and are often less visible than a mobile phone app or an on-line dictionary when they occur within existing institutional structures and do not draw media attention. Additionally, the creation of a learning space necessitates the creation of Diidxazá teachers and learners as recognizable social categories or identities, a process which is also likely to be slow. The creation of learning spaces inevitably fosters increased Zapotec communicative practices within them as well, an occurrence that may be rapid and ephemeral or enduring if learners incorporate language use into their lives over time.

Activists' initiatives may have a socio-historical orientation towards the past, such as the website created by the Fondación Historico-Cultural Juchitán, or towards the present and future, such as the Raptivismo hip-hop radio show. Initiatives may follow an orientation to diversity which prioritizes what is perceived as more or less unitary or pure communicative and cultural practices, such as the Guca'nu jneza diidxazá [Let's write good Zapotec] social media page. In contrast, they may orient towards what is perceived as syncretism and 
hybridity, such as the feminist collective Las nietas de lxs Binnigula'za [The granddaughters of the [male and female] Zapotec ancestors], or they may slide between the poles of this continuum in relation to different issues. Finally, activists may aim to create a participatory, negotiated space, such as a social media site intended for discussion, or they may exert various levels of control over what is created, such as authorial and editorial choices made by scholars or artists.

Some targets can be created relatively rapidly by an individual or a small group, such as learning materials or an event. Other strategies take much more time and require a wide coalition, such as the creation of a structure, or a recognized identity. In the pursuit of creating these socially- and structurally- embedded changes, I observed the following strategies of connecting and representing to be especially significant.

\subsubsection{Strategic connecting}

While strategies that create something may often receive more attention due to greater tangibility and novelty, strategies of connecting are also of crucial importance in language activism. Strategic connecting seeks to change the way that existing actors, resources, spaces, identities and/ or communication practices relate to each other by building or strengthening networks and relationality. Examples of some of the strategic connections which Diidxazá language activists make include:

- Resources to other resources, to spaces and to people, such as the production of databases, dictionaries, and libraries (chapter 3) or the Camino de la Iguana teachers giving away books (chapter 6).

- Events to people, such as inviting participants to a conference on the radio (chapter 3) or inviting children to a workshop (as mentioned in the opening of this chapter).

- Spaces and structures to people and to communication practices, such as involving parents in primary school activities (chapter 4), and using Diidxazá in the university (chapter 5).

- People and identities to resources and to each other, such as taking studentteachers to a specialist library and introducing them to more experienced teachers (chapter 5), and encouraging people to discuss writing norms together in a social media space (chapter 7).

- Communication practices to people, such as speaking Diidxazá to children as part of a workshop (as in the opening of this chapter) or providing an online translator with audio pronunciation for learners (chapter 7). 
Ways of connecting can be rapid and of low visibility, such as an invitation or a personal introduction, or more longitudinal and higher visibility, such as the creation of an archive or coordinating an exchange between two institutions. For example, the teachers and director that invited families to participate in activities designed to valorize local culture in their primary school took an action that was fairly quick (the invitation) and resulted in raised visibility (chapter 4). The creation of the activities was obviously more time-consuming, but inviting parents to participate in the activities once they existed was a strategy that made the activities rapidly more inclusive and more convivial. A quick connection may be the first, necessary step in strengthening a network or community of practice. For example, an introduction between student-teachers and more experienced teachers made a contribution towards the development of Diidxazá classes in a university space where none previously existed, but actually solidifying this structural change is a much longer-term goal which requires many other supports along the way (chapter 5). Connections between members of different communities of practice can be advantageous in order to strengthen activist networks, such as between teachers in different contexts, or between transnational researchers and local activists (chapter 8).

Collecting resources or information, such as the creation of an archive, can also be viewed as a form of connecting. The creation of a collection or archive can serve to pool resources, and to connect people to these resources, especially when publicized on-line. Decisions about what to exclude are inevitable however, and the knowledge or objects to be archived typically go through considerable manipulation as they are prepared for conservation, making this generally a more closed form of activism. The Smithsonian ethnobotany project resulted in an archive and eventually a dictionary of plants which grow in the Isthmus along with their Spanish, Latin, and Diidxazá names, made accessible on-line through the Smithsonian National Herbarium. Which languages to use, including which plant name(s), was an editorial choice made by the research team. Use of both Spanish and Diidxazá was a priority in order to make the collection accessible to viewers in the Isthmus, and fortunately the on-line format allowed for a multilingual approach more readily than printed materials.

Static forms of connection, such as a collection, are dependent on access and visibility in order to result in social benefits, whereas human connections are perhaps less longitudinal, but can much more readily result in convivial interactions and actual communication practices. For example, by giving a book of Isthmus Zapotec texts to a library in Santa María Xadani I made them more widely available. By giving a copy of the book directly to a teacher trainee who was developing an extra-curricular program for elementary children, I had a much greater assurance that actual benefit might result from my action, as 
I hoped that he would use the texts in support of his teaching and thus eventually the production of communication practices among his students. Connecting can thus be a way to resist current inequalities, such as lack of resources or access, or the marginalization of certain people and communication practices (such as Diidxazá-speaking parents) from important social spaces (such as school).

\subsubsection{Strategic representing}

Ways of representing- discursively framing something (or someone)- occur constantly in conjunction with other strategic actions, and are themselves an important contribution to language politics. Representations tend to be fairly rapid in comparison with other strategies, but may build up over time, leading to longlasting impacts. Examples of the representations of language activists include:

- Resources, such as designing didactic materials to be attractive or sophisticated (chapter 3), or promoting Zapotec hip-hop as cool on the radio (chapter 7).

- Events, such as the posters and fliers that advertise workshops and events by depicting them as fun or in some way appealing (chapters 6 and 7).

- Spaces or structures, such as the representation of higher education as a site where local languages are valued (chapter 5), and the Isthmus region as space where Diidxazá literature is vibrant (chapter 6).

- People or identities, such as memes that praise or ridicule young Zapotec speakers (chapters 5 and 7), and teachers that show respect for students who speak Indigenous languages (chapters 4 and 5).

- Communication practices, such as promoting multilingual communication as legitimate (chapter 3) or promoting multiple dialect variants as legitimate (chapter 6).

While all Diidxazá activists engage in positive representations of Diidxazá speakers and/ or language use, there are differences in the discourses of locally-affiliated people versus non-locally affiliated advocates. In my observations, local advocates engaged in representations in more personal and specific ways, such as praising an individual writer, or telling a story about a Juchiteco who attended a bilingual school and went on to become a Doctor. Non-local advocates on the other hand were more likely to promote the benefits of multilingualism in general ways, or take up the "language as universal heritage" and "treasure" tropes cautioned against by Jane Hill (2002). The former focuses on the creation of positive representations in relation to Zapotec speakers, while the latter focuses on representing abstract phenomena- multilingualism, and the language itself- as valuable and desirable. The 
representations made by actors in positions of power at different social scales may be more visible or circulate more than others, such as when researchers are interviewed on the radio or their work is represented in the newspaper.

Orientations to history, diversity, and participation are often significant factors that shape the representations of activism initiatives. For example the social media page, Guca'nu jneza diidxazá [Let's write good Zapotec] orients towards a somewhat purist or normative view of Zapotec writing, while at the same time encouraging open participation and discussion through a public social media page. The teachers at the Tehuantepec Faculty of Languages attempted to represent multiple regional dialects as equal, but they were challenged by expectations (theirs and in some cases those of students) of a standard, unitary writing norm. The Camino de la Iguana teachers oriented towards the history of Diidxazá literature, while also including and promoting contemporary literature, including praising the hip-hop and feminist movements described in chapter 7. Finally, while many residents of the Isthmus represented Diidxazá as a communicative practice which did not include children nor recent migrants to the region, many activists resisted this and represented an inclusive and participatory Diidxazá speech community. Strategies of representation thus have an important role to play in influencing social imaginaries about legitimate language and identities in the Isthmus.

As discussed from chapter 1 onwards, my objective has not been to identify 'successful' strategies, or 'the best' technique, as I do not believe a one-size-fits -all solution is possible. I do wish to draw attention to the value of strategies which often receive less attention and praise, yet which I argue are also crucial pieces of the language politics puzzle. If activists hope to counter structural inequalities and exclusionary socio-political processes there is a need to design effective strategies to chip away at these inequalities in their context. In the following section I reflect on the characteristics of strategies from local to global scales, and the benefit of locally-grounded strategies. While one of the arguments of the language activism strategy framework is that all strategies are of value, in my observations some kinds of strategies and some theories of change receive more attention and recognition than others, and undeservedly so.

\subsubsection{Characteristics across scales and activist positionality}

In analyzing a range of activism strategies, I have highlighted aspects that I observe to be especially important in defining the nature and potential kind of impact of the strategy. These strategy characteristics are presented in chapter 1 (see Figure 2), and have been discussed in relation to specific initiatives throughout the book. Examples of activism strategies with different characteristics drawn 
from the chapters of this book are illustrated in Table 7 below. As argued multiple times, all of these characteristics have something to offer, and may be an effective choice for a particular moment. In some cases, the characteristic may be easy to shift; for example making a pedagogical grammar available in a digital as well as print version will increase the mobility and likely also the visibility of the resource. A workshop or learning resource drawing primarily on historical, past motifs can incorporate a more contemporary style relatively easily if the creaters choose to do so. Additionally, the degree of participation in many ititiatives can be changed throughout the initiative by choosing to find ways to invite a wider range of stakeholders to have a role (such as crowd-sourcing approaches to language documentation, rather than a traditional linguist-speaker model), or choosing to narrow down the number of participants in order to move ahead and complete a project quickly (such as a small team of teachers producing a lesson plan after collecting input from an open group of parents and community members).

Table 7: Examples of language activism strategies with contrasting characteristics.

\begin{tabular}{ll}
\hline Characteristic & Scale \\
\hline Location: & Local $\leftrightarrow$ International \\
\hline- E.g. Hip-hop events & $\begin{array}{l}\text { Created through local networks, drawing on global } \\
\text { culture }\end{array}$ \\
\hline - E.g. Primary school class project & $\begin{array}{l}\text { Local participants; some influence } \\
\text { from national policies }\end{array}$ \\
\hline Timeframe: & Slow $\leftrightarrow$ Rapid \\
\hline- E.g. Teacher education & Learning \& practice over years \\
\hline
\end{tabular}

- E.g. 2-day seminar for teachers

Several months to plan; relatively rapid

\begin{tabular}{llll}
\hline Visibility \& mobility: & Low & & High \\
\hline - E.g. Social media posts & & Fast, extensive circulation \\
\hline - E.g. Pedagogical grammar in print & Limited copies \& circulation \\
\hline Socio-historical orientation: & Future & $\leftrightarrow$ & Past \\
\hline
\end{tabular}

- E.g. Literacy workshop Explicit ties to both past and present

- E.g. Website with archival/

Focus on past

historical content

\begin{tabular}{|c|c|c|c|}
\hline Diversity orientation: & Syncretic & $\leftrightarrow$ & Purist \\
\hline - E.g. Univeristy language classes & $\begin{array}{l}\text { Efforts to } \\
\text { Standard }\end{array}$ & $\begin{array}{l}\text { Itiple } \\
\text { deolog }\end{array}$ & $\begin{array}{l}\text { varieties } \\
\text { ies remain influential }\end{array}$ \\
\hline
\end{tabular}


Table 7 (continued)

\begin{tabular}{ll}
\hline Characteristic & Scale \\
\hline Participation: & Open participation $\leftrightarrow$ Controlled participation \\
\hline- E.g. Cultural events & Open participation encouraged \\
\hline $\begin{array}{l}\text { - E.g. Traditional language } \\
\text { documentation }\end{array}$ & \\
\hline
\end{tabular}

One characteristic that is harder to adjust is the location and identity, or positionality of the person or people involved in the initiative, whether they have primarily local ties or primarily non-local ties. The actions of non-local activists in the Isthmus tended to focus on resources, including producing, publicizing (representing), and accumulating (connecting) texts, recordings, videos, and didactic games. They also engaged in producing and publicizing events. Events and resources are generally highly visible and lend themselves well to widely circulating positive representations, such as articles in online media. Some resources also lend themselves to geographic mobility, such as mobile phone apps and downloadable grammars and dictionaries. Considering that non-local advocates are by nature not, or at least less, embedded in local institutions and daily life than local Diidxazá advocates are, it is not surprising that their actions focus more around mobile and short-term targets such as resources and events.

The most common strategies of local activists, on the other hand, are indicative of their position within place-based networks and their potential for long-term engagement. Local actors engaged in representing, connecting and producing across all analyzed areas, but unlike non-local actors their actions most often targeted people, communication practices and spaces, with less attention to producing resources or one-off events. Some of these strategies have lower visibility, and thus may receive less praise and attention. A grandparent who chooses to use Diidxazá with their grandchildren at home, or a teacher who presents and praises the work of Zapotec writers to her class, are making important contributions to the kinds of communication practices and representations that children will grow up with. Likewise, a musician who chooses to make bilingual music and share it with their peers is influencing representations of language and culture. These kinds of strategies may seem limited in terms of the timeframe they occur in and how many people participate in them, and there may be little or no tangible evidence of the strategy after the fact. Yet in these ways local activists help to tackle 
persistent prejudices and reimagine the relationship between language and social status. As Mayoli García, the language activist and university student quoted in the opening of chapter 1 stated, "Hasta que no crees una conciencia real en las personas, no va a haber eso" [Until you create a real awareness in people, it won't happen]. Changing the status of Isthmus Zapotec speakers, and countering the marginalization of the language requires strategies with the intangible goal of creating a different social imaginary, as well as tangible goals such as creating more equal resources and structures.

During the course of my fieldwork in the Isthmus I often reflected on tangible versus intangible strategies, as well as when to speak up and offer an idea or initiative, and when to listen and observe. I gradually shifted away from my initial interest in producing resources, and towards a focus on supporting existing networks and spaces (see also chapter 3). During fieldwork I regularly wrote reflective memos on my own initiatives; in one memo entitled "Things and non-things" I recorded my on-going doubts:

A focus on creating 'materials' is limited. It makes these things seem like the solution to much broader problems. Now that I've [. . .] gained a clearer focus on the limits of focusing on materials, I realize I often do the same thing- make it sound like the whole focus is the production of some 'thing'. Producing a 'thing' is the simplest way to demonstrate support though, so I'm not sure how to get around this. Much like the limitations of focusing on language as a 'thing', an object. We know it's not accurate, but it's hard to get out of that way of talking \& thinking.

(Memo December 2014)

Although I still asked people about materials or supports that they might be interested in having, I began to shift my focus towards strategies of connecting people and existing materials, and fostering learning spaces. I also started to question the assumption I had made that the production of material things is "the simplest way to demonstrate support", noticing that this focus on materialism was influenced in part by my cultural background as a settler-European American. As a scholar activist, the strategy of creating resources and providing the greater visibility that my social position allows me to contribute to a certain extent, does remain important to me. I have observed many positive impacts from the materials and events that other scholar activists have created, and I am confident this strategy will continue to be important in many minority language contexts. At the same time, I believe more energy could be invested in working with teachers and institutions (people and spaces, in the terminology of the framework) on issues of quality and sustainability, as experienced by the local educational community. Additionally, supporting the work of artist activists is crucial in the process of reimagining more equal futures for minoritized languages. 
This work is slower, generally less visible, and more local in scale, but has the potential to create a meaningful change.

From attempting to inventory resources, to creating events for larger scale connection of people, and producing long-term learning spaces, I certainly never felt that I ran out of possible strategies to try while working in the Isthmus. As a scholar activist, the strategies outlined help me to better conceptualize my work in socially engaged ways, and to fulfill my goal of conducting ethnography in the service of critical reflection and social change within a constructivist paradigm. With the recognition that policy is performed and negotiated across social scales, the repertoire of strategies described in this study may be useful to actors seeking to participate effectively in the politics of minoritized language advocacy from varying positions of social power. The need to go beyond state-centric paradigms of policy and social change has been well established; the strategies discussed here are offered in contribution towards furthering participatory ways of understanding and undertaking language politics. Many actors are not in a position to frame their goals as state authorities would, and more importantly many may choose to avoid framing their goals in positivist or top-down ways. It is not necessary to be an insider to engage in contextualized, meaningful strategies; nor is it necessary to be internationally or politically connected to engage in impactful strategies. Language activists pursue different goals in relation to their social position, priorities, and the theory of social change that they hold. A social constructivist approach to engaging in language politics, as illustrated through examples of Diidxazá activism, requires flexible practices, creative reimaginings, and tenacious resistance from a variety of standpoints.

\subsection{Engaging in social change through language}

In the Isthmus, as in other multilingual contexts, there are varying views of what a desirable language ecology would look like, and inevitably varying imaginaries of what constitutes positive social change. While some parents are pleased to have Diidxazá increasingly taught in school, others oppose it. School directors or parents who use only Spanish with children in the Isthmus are pursuing a monolingual future they view to be better than their multilingual past and/or present, in which they hope that the new generation will not experience discrimination or material need. Engaging in language activism despite the multiplicity of evaluations or perspectives present among diverse stakeholders has many pitfalls; certain forms of engagement may be viewed positively by some actors and negatively by others. 
The framework of language activism strategies in this book, aiming to include a wide range of actors across contexts, does not incorpate measures for judging or evaluating these strategies. This is intentional. In our own contexts we may observe that certain strategies seem to have a larger or more lasting effect, and that certain activists make what seem to be more powerful efforts, while others make efforts that seem less engaged. These differences do matter of course - a strategy such as liking a social media post in a minoritized language is not the same as a strategy of writing and publishing bilingual literature, or organizing an event. In activist communities of practice there are typically some people who are the charismatic core and leaders of initiatives (e.g. Hornberger 2017), and others who participate in more peripheral ways. By arguing for the importance of small, less visible forms of activism I do not want to draw attention away from the trailblazing work of dedicated leaders, which is indeed at the core of every minoritized language initiative I am familiar with, in the Isthmus and elsewhere. I encourage evaluation and reflection of one's own activism initiatives, and learning through observation of others, but I am not interested in attempting to judge or compare activism strategies out of context, nor in relation to a universal notion of what 'good' activism must be. These are important questions to ask and discussions to have within language activism initiatives.

For example, Johnson (2013) lays out concrete strategies for teachers and researchers aiming to promote multilingual education in public schools in the US, including building local coalitions and influencing key power-brokers through legal and media channels (188-214). In this context, it is valuable to have prescriptive guidelines about what kinds of letters to the editor might get published, and tips for putting pressure on politicians. Under some circumstances, activists may find it necessary to demand a certain level and kind of participation. However, Johnson also emphasizes the importance of open participation and different kinds of contributions to language politics. He argues for "changing participation frameworks to empower a diversity of language policy agents” (2013: 191), and a paradigmatic shift whereby researchers, teachers, and parents come to view themselves as language policy makers. In the context of scholar engagement in language revitalization, Whaley (2011) cautions against scholars trying to assume control of a revitalization initiative in the way they typically aim to control a research project. The more open or convivial the form of participation in the activism initiative is, the more likely that there is room for different kinds of contributions.

Based on my observations and participation in language activism in the Isthmus, I also argue the need to facilitate open participation and to make space for diverse imaginaries within language activism initiatives. How contrasting priorities and evaluations play out in activism initiatives, and the power dynamics 
among charismatic leaders and people who make up the wider networks of support are often a challenge, however. Many initiatives come to an end for these reasons. The encouragement to include different voices and potentially multiple priorities is in no way easy or straightforward. This is the case in all forms of activism, whether the focus is on inclusive language education or land rights. Further discussion of the struggles within initiatives and 'what not to do' could be beneficial to other language activists, however I believe an academic book is not the most useful place for that. Throughout this book I have chosen to focus on examples of relatively successful initiatives that I have observed, and to reserve critical reflection primarily for scholar-activist strategies (including my own). In the following sections I discuss what the activism strategies examined in this study have taught me about possible ways of working with multiple understandings of language (8.2.1) and multiple theories of social change (8.2.2).

\subsubsection{Diidxazá as a deictic}

As examined in chapter 1, and throughout this book, 'Diidxazá', and indeed all languages, have multiple meanings for the varied social actors who engage in language activism. Understanding the deictic or indexical nature of Diidxazá is helpful when engaging in activism initiatives. Linguistic anthropologist Michael Silverstein (1976) defined deictic shifters as words which gesture towards specific people, places, or times, having no independent referent out of context. Indexicality is likewise a useful framework for understanding how language is always intertextual and takes its meaning from other times and places (Bauman and Briggs 1990; Briggs and Bauman 1992). The deconstructivist tradition in the philosophy of language suggests that all words and speech, not just certain deictics, acquire meaning through indexicality with an absolute meaning indefinitely deferred (Derrida 1967). By discussing the ontology of Diidxazá (and named languages in general) as deictic I am not promoting extreme deconstruction of meaning nor a solipsistic framing; rather I locate the construction of mutually available meanings within different social groups or communities of practice, as part of their shared repertoire or social imaginary. This is one way to achieve the postdeconstructivist "reconstituting" discussed by Makoni and Pennycook (2007); by understanding minoritized languages as placeholders, windows, perhaps even magnifying glasses onto a variety of social phenomena and shared concerns.

Integrating an understanding of the inherently multiple ontologies of Diidxazá into language activism is helpful in considering diverse imaginaries of language use that are present in any one context. For example, the approach that Istmeño scholar-educator-activist Víctor Cata has developed in his work as co-facilitator of 
the literacy workshop Camino de la Iguana is based on his multi-level understanding of Diidxazá, as discussed in section 6.3.1. Although he promotes reclaiming the use of words and concepts which are not in common use today, in line with his appreciation of Diidxazá as a repository of cultural and historical knowledge, he also notes that for some speakers and learners Diidxazá is tied up with personal feelings of insecurity. With this understanding, his strategy as a teacher includes avoiding creating further negative feelings. As he commented (quoted in full in 6.3.1) "si de por sí no habla y aparte les digo que no hablan bien . . . . . . .] mejor que hable, ya sobre la marcha ya aprende." [if in fact someone doesn't speak and besides I tell them that they don't speak well ... . . . .] it's better that they speak, then learn along the way]. I observed Víctor's ability and willingness to shift between his perspective as a linguist and historian, and his perspective as a teacher and member of the Zapotec-speaking community to be a valuable asset in his work as a language activist.

I aimed to apply a similar deictic perspective of Diidxazá in a presentation that I gave to a local audience in the Isthmus (one of several times that I gave public presentations as a way of sharing back my research and receiving feedback), where I analyzed the question “¿Por qué parece “dificil” escribir en diidxazá?” [Why does it seem to be 'hard' to write in Diidxazá?] (Field notes July 2015). On many occasions I have been told by Istmeños that they find writing Diidxazá to be hard; it is a source of pride and for many an important part of their aspirations and imaginaries of their future language use, and yet at the same time many find it daunting. In my analysis of this concern, I identified phonetics, phonology, schooling, and ideology as key domains that contribute to the perception and experience of difficulty. I began with a discussion of language attitudes and ideologies, asking the audience what makes a language 'useful', followed by a discussion of what makes a language 'difficult'. The goal was to highlight that 'difficult' is a social construction in some ways, just as 'useful' is, in a context where learning the foreign language English is not considered too difficult to attempt, despite a much less transparent orthography. In order to show how the perception of 'difficulty' is created, I turned to the level of linguistic features, discussing the relation between the phonemes of Isthmus Zapotec and how they are represented in the popular alphabet, and identifying contrasts with the phonemes of Spanish and their representations. I then discussed phonetic and phonological elements which are not represented in the popular alphabet (tone and stress), but which do play a role in meaning making (i.e. are contrastive features), and whose absence sometimes confuses beginning writers and readers in my observations. I then discussed the past and present schooling practices in the Isthmus, which have not only focused uniquely on Spanish as a language of reading and writing, but have also delegitimized and devalued Diidxazá through exclusion and punishment of 
speakers. I also mentioned that the popular alphabet is an unenforced and polynomic norm, yet the exposure to standard language attitudes in schooling makes many people apply prescriptivist expectations onto Zapotec writing. In conclusion, I argued that greater metalinguistic awareness of the features of Diidxazá and contrasts between Diidxazá and their current (Spanish) repertoire, as well as confidence and opportunity to appropriate Diidxazá writing, could considerably enhance the experience of Diidxazá learners and lower their perception of difficulty in the process of learning to write.

In order to bring together appropriate knowledge to tackle such problems, it is useful to adopt linguistic, social, educational, and ideological perspectives on Diidxazá, without the need to privilege any one perspective. When I began this study, I was interested in ways of bringing different actors with different perspectives into conversation, and finding shared perceptions and common denominators, such as the inclusion of minoritzed speakers. I am now less interested in forging common understandings across communities of practice, and more interested in normalizing a multi-perspectival or indexical approach to minoritized language activism. The way that a language is understood within a community of practice may be relatively coherent- as a medium of convivial interactions in the Camino de la Iguana classes, or as a valuable code and source of knowledge in documentation projects for example. One solution would be to limit the scope of an initiative and work only within an activism initiative where there is a shared social imaginary and goal. This approach could miss out on the possible coalitions and networks that I have observed to be so crucial among language activists however. It is worth working together, even if there will never be large-scale coherence across the different communities and disciplines engaging in issues around language. Perhaps I am returning to an inclination towards Whorfian worlds of thought which drew me to study language diversity many years ago, or I am simply becoming more realistic about the affordances and limits of interdisciplinary collaboration. Regardless, I expect that my perspective will continue to shift as I engage in future projects. At present I am hopeful that more awareness may develop around the plurality of perspectives among minoritized language activists in particular, which would be helpful in building future knowledge and strategies in this area.

In particular for scholar activists, engaging with different paradigms or ontologies of language is crucial if we are to avoid reproducing the coloniality of previous research practices. Scholar activists who are not members of the community they work in can take an "allied stance" and help to provide a platform for the perspectives and imaginaries of those who have been marginalized (Anthony-Stevens 2017). Problematizing and probing common concepts, such as 'language' and 'revitalization' is an important step in this direction 
(Leonard 2017; Davis 2017). A constructivist research project that aims to contribute to positive socio-political change must adopt some reductionist concepts and/ or perspectives in order to identify positive potentials and communicate about them with a wider audience, while a pragmatic project that aims to contribute to change must take seriously the constantly-shifting, locally-specific place and people from whom change might emerge. As I hope to be able to have productive conversations in both local spaces and the centralist spaces of government and academia, I have found it useful to work towards a research repertoire that includes these different paradigms, their discourses, and their theories of social change.

\subsection{2 'A grain of sand' theory of change}

In addition to the concern of what positive change looks like, there are different understandings of how social change occurs. Is change produced through topdown government policy? Can individual actors incite change? Is it something that can be negotiated within a local community of practice? Is it primarily about resisting and tearing down the structures of inequality? Or about building and creating new structures? The focus on creation of materials and awareness-raising events and publicity that I observed among non-local scholar activists, including myself, aligns well the "theory of error correction" which has characterized the outreach activities of language scholars for decades (Lewis 2018). Within this theory of action or change, what is needed in order for Diidxazá to be transmitted are adequate learning or reference materials (acquisition and corpus planning, in the standardized nation-state tradition) and the presentation of sufficient scientific evidence as to the benefits of multilingualism and/ or the imminent loss of language and thus knowledge. The implied theory of action is that people's behavior will then logically shift when the right materials and the right argument have been presented to them. Correcting misinformation may indeed have some effects on peoples' perspectives, and improving the availability and access to materials is also a tangible step towards greater language equality. But none of these valuable contributions are in themselves a solution to the complex factors that perpetuate language-based inequalities.

On the other hand, local activists often described their efforts whether in teaching, learning, writing, performing, or otherwise promoting Diidxazá as the way they "aportar su grano de arena" [contribute their grain of sand] - not expecting to bring about a radical shift in the language ecology, but doing something that they feel has value. While proud of their work, many Zapotec 
activists are aware that it is not of interest to all of their neighbors. The creation of educational spaces, public use and valorization of Diidxazá, and modest expectations as to the outcomes of their work point to the influence of a more constructivist and non-teleological theory of change, where numerous contextual factors and others' agency will all influence the outcome of any attempt at social intervention. The strategies of these activists reflect a place-based understanding of the context they are working in; an environment that they experience as a complex whole, where incremental changes may be possible if lots of people get on board, but nothing will shift overnight.

Among local-oriented activists the use of conviviality is also a common factor, both through person-to-person interactions and more ritualized convivio events such as bestowing participant certificates, organizing public readings, or incorporating music and art into a conference. The ideologies and imaginaries that independent group members bring with them are inevitably crucial factors in how language practices and norms emerge in a community, but in a convivial paradigm they are negotiated among the group. For example, the interest of some Diidxazá students and teachers in conserving pre-Spanish words and ideas is present in education initiatives, while other students' interest in learning the repertoire of the modern market and appreciation for syncretic language use also has a place. Prescriptivism and purism do not need to disappear from the social imaginary of the group, as long as they are subjected to a process of convivial negotiation rather than being imposed as norms. In observing language activism initiatives in the Isthmus, practices of convivencia or conviviality emerged as a significant characteristic facilitating the positive outcomes of these social projects.

The underlying theories that influence the strategies of different actors are evident in the following vignette from the final day of a four-day linguistic workshop on tone in Diidxazá run by Gabriela Pérez Báez who was in the Isthmus on a research trip and was excited to facilitate an open workshop for interested participants.

Throughout the 4 days of the workshop Gabriela has explained the phonology of Diidxazá with a focus on lexical tone. She uses examples and interactive exercises with a group of around 8-10 adult participants. Attendees are mainly teachers and retired teachers, plus Gabriela's colleagues Víctor Cata and myself. At the end of the final day, she shows them several different possible ways to represent lexical tone in writing, including the popular alphabet, which does not represent it consistently. She would like to represent it in the dictionary that she is preparing, but she wants speaker input in order to choose the approach that they prefer. At several points Gabriela and the participants discuss that "if in 100 years there are no speakers" this writing system should represent as much phonological detail as possible. She says she knows it has been a quick workshop, but she would 
like to know if they think that tone should be represented, and if so how? Most participants have been fairly quiet throughout the workshop, and this question is also initially received with silence. Then Víctor jumps in: We need to practice, we need time to experiment with different approaches before deciding, he says. Others nod. Gabriela agrees, it would be helpful to try the styles with children and different potential users, and to use them on social media she notes. She wonders how to resolve this question in a timely manner though. A man comments that writing is so much harder than speaking- he only understood the vowel phonations for the first time yesterday (a characteristic much simpler than the tonal patterns that Gabriela has been explaining, and which is already represented consistently in the popular alphabet). In the end, everyone agrees to Víctor's suggestion that they should try using the different approaches for a while and come back with more input at a later time.

(Field notes August 2013)

From activist linguists working to create a transparent representation of sound patterns for posterity, and local educators who want any new norms to be as accessible as possible, the perspectives and priorities of stakeholders in just one workshop event are clearly very diverse. Gabriela had initiated a participatory approach to getting input through the workshop, and Víctor built on this to propose further interaction and practice over an extended timeframe. The participatory solution proposed by Víctor and readily endorsed by Gabriela is an example of a convivial approach to language activism, where collaboration in decision-making and in processes of social change are promoted. The importance of participation and investment of the wider speech community in language activism initiatives has been established in other minoritized communities (Urla et al. 2017). This approach is also inevitably slower, and subject to many perspectives, and incremental contributions or 'grains of sand'. The social meanings of Diidxazá use will always be multiple, however among voluntary participants and activists the aim to resist structural inequalities and enact equality from the ground-up contributes to a social imaginary in which historical inequalities begin to lose some of their social meaning and hopefully also their impact.

This framing is in line with an interest in social projects as a scale where new spaces and practices may emerge in support of marginalized groups which resist homogenizing national and international governance (Povinelli 2011). It is also in line with social and political life in the Isthmus, where there is universal distrust of national and international government (and corporate) interventions, and intricately structured social networks. The backbone of social life in the Isthmus is the reciprocity performed among social networks, through voluntary labor (guendaruchaa, guendalisaa, tequio or trueque), attendance at parties, godfather/ mother (compadrazgo) duties at birth, school graduations, and weddings, among other forms of communality (see e.g. Mintz and Wolf 1950; Royce 1975, 2011, also chapters 2 and 7). In this setting, the most effective way to contribute to social improvements thus appears to be through collaboration and social networks, rather 
than structural or official interventions. As has been argued in relation to individual policy actors (Ricento and Hornberger 1996; Shohamy 2006), it is clear that social networks are also important mediators of language politics, especially in contexts like the Isthmus.

As discussed in chapter 1 and above, I am interested in strategies of engagement not just to describe and analyze this political phenomenon, but also from a practitioner perspective, viewing myself as a social actor with potential to participate in language and education politics, and aiming to do so in appropriate and creative ways. Traditional approaches and types of language policy have privileged the perspective of a state or government decision-making authority, with less insight into local language politics and ideological dimensions, a bias critiqued by Canagarajah (2005), Johnson (2013), and Davis and Phyak (2017), among others. Along with these scholars, I argue that a wide range of people are potential activists and agents in language politics. As such, we can learn from activists who are choosing to engage in language politics within different social spheres or communities of practice, and from attending to the underlying imaginaries and theories present in their activism strategies.

\subsection{Summary: Convivial language activism}

It is one thing to acknowledge that working towards positive social change in an intentional, strategic way requires adapting to multiple perspectives and not expecting a final solution - it is another to sustain the energy, motivation, and humor necessary to keep working at it without the possibility of ever achieving unanimous support or complete success. Minority language activism is no different from any other field of social activism in this respect. The politics of (Indigenous) language activism will inevitably remain a site of contention over group boundaries and other social ideals. Social imaginaries of language, identity, and education must be negotiated again and again across social scales, whether in policy documents, program models, classroom interactions, or popular culture spaces. From this point of view, language inequalities are problems that have no final resolution, a conceptualization that differs from the problem-solving orientation inherent in much language planning and educational development work. As such it is worth considering whether a problem-solution theory of social change is appropriate to work on Indigenous language activism, or whether it is more appropriate to view our improvements and interventions in another light, such as participating in the creative design of social futures (Cazden et al. 1996), supporting processes of decoloniality through linguistic self-determination 
(Leonard 2017), or contributing grains of sand to a hill whose growth may only be visible many years from now.

Being an activist in language politics in today's local-global language ecologies requires ongoing creativity and adaptation of political strategies. With official recognition of Indigenous languages a reality for nearly two decades in Mexico, national policy has so far created few new ideological and implementational spaces of language equality, as discrimination and Spanish monolingualism remain the promoted norm. Policies of recognition ("language rights") in Mexico and elsewhere have not resulted in greater social equality, as minoritized communities continue to be denied necessary material rights and resources under neoliberal economic systems (Hale 2005; Muehlmann 2009; Overmyer-Velázquez 2010; Povinelli 2011). The effort to change inequalities on the ground must clearly go beyond state-generated, rights-oriented approaches to language planning and policy and the small spaces of opportunity that recognition policies do open up.

This book has aimed to show that there are many strategies that Zapotec language activists employ across diverse communities of practice. There are some common ways that activists engage in representing, connecting, and creating resources, events, spaces, people, and communicative practices, such as positive representations of Indigenous language speakers and communicative practices, and creation of learning spaces and/or materials. There are also differences shaped by contextual factors such as the social positioning of actors and the constraints and affordances of time and visibility. These include tendencies towards production of rapid, mobile resources, versus slow, placebased structures. Conceptual factors, such as the meanings that Diidxazá holds within different communities of practice and underlying theories of action, also influence how strategies are developed and employed, as advocates envision success to be different, and to be achieved in different ways. The valorization and inclusion of Diidxazá remain common goals however, whether through socalled expert planning and influence, or many small grains of sand- or both.

Throughout this book I have aimed to increase the visibility of some of the Diidxazá speakers, learners, and activists in the Isthmus, although it is inevitably a partial perspective and there are many brilliant activists whose work has not been mentioned here. As one young teacher, Carlos Antonio Celaya Gómez commented at the end of an interview when I asked if there was anything else he would like to say:

Pues, que si alguien llega a escuchar eso que sea aquí de la región o de la universidad donde vas a presentar, que se animen a venir a visitar a la región o el estado, a conocer un poco más de esa cultura y de la lengua. Para que no solo escuchen "zapoteco, zapoteco, zapoteco" en tu investigación y en las documentaciones que hagan. Que realmente lo conozcan tal cual es, el contexto y todo eso. 
Well, that if someone hears this that is from here in the region or in the university where you're going to present, that they should get motivated to visit the region or the state, to know more about this culture and the language. So that they won't just hear "Zapotec, Zapotec, Zapotec" in your research and in the documentation that's made. That they really get to know it how it is, the context and everything.

(Interview July 2015)

I wholeheartedly echo Carlos' caveat to my (and all academic) work- and his suggestion to visit the region, made with the tone of pride with which residents of the Isthmus often describe their homeland as unique and a place worthy of note. At the same time, I view this comment as another example of the convivial norm typical of Diidxazá activists, where personal interaction and participation are prioritized. For those unable to take up the invitation, I hope that my observations and interpretations presented here offer a view of the dynamic sociolinguistic ecology of the Isthmus of Tehuantepec and the ways that language activists are charting paths towards linguistic equality through diverse strategies of resistance and reimagining. 
